\title{
Influence of Haze-Fog on Consumers' Desire for Money
}

\author{
Liangmu Wu, Feifei Yang \\ Business School, Shanghai University, Shanghai, China \\ Email: feifeiyang@i.shu.edu.cn
}

How to cite this paper: $\mathrm{Wu}, \mathrm{L} . \mathrm{M}$. and Yang, F.F. (2019) Influence of Haze-Fog on Consumers' Desire for Money. Open Journal of Social Sciences, 7, 190-208. https://doi.org/10.4236/jss.2019.71017

Received: December 20, 2018

Accepted: January 19, 2019

Published: January 22, 2019

Copyright (C 2019 by author(s) and Scientific Research Publishing Inc. This work is licensed under the Creative Commons Attribution International License (CC BY 4.0).

http://creativecommons.org/licenses/by/4.0/

\begin{abstract}
With the increase of haze-fog, it seriously affects the people's quality of life. Most studies link haze-fog to diseases, environmental issues or governance and policy. However, the relationship between haze-fog and psychology and behavior remains relatively underexplored in the psychology literature. Drawing from regulatory focus theory, this paper explores how haze-fog influences individuals' psychological states and behavior. Specifically, we design an experiment to examine how haze-fog influences consumers' desire for money. Results indicate that haze-fog is negatively related to consumers' desire for money $\left(M_{\text {sunny day }}=3.79, M_{\text {moderate pollution }}=3.99, M_{\text {severe pollution }}=5.49\right.$, $F(2,105)=10.67, p<0.01)$, and the perception of defensive psychology mediates the relationship between haze-fog and consumers' desire for money (95\% CI [0.0102, 0.7597]). This paper shows that haze-fog does not only influence our life, but also our purchasing intentions. It reveals that when haze-fog is severe, it evokes consumers' defensive psychology, and then it decreases consumers' desire for money. Future research can focus on the other haze-fog related consumer psychology and explore haze-fog related marketing.
\end{abstract}

\section{Keywords}

Environmental Pollution, Defensive Psychology, Regulatory Focus Theory, Haze-Fog, Desire for Money

\section{Introduction}

Rapid industrialization and urbanization in emerging countries help people escape from poverty, thus increasing social employment opportunities and benefiting society [1] [2]. However, many areas in emerging countries suffer from frequent air pollution (no matter indoor or outdoor), which negatively affects 
society and the residential environment. Among the environmental problems, haze-fog has become people's main concern in recent years [3]. Fog refers to the visible combination of very small droplets or ice crystals suspended in the air near the ground. Haze refers to the condition mainly caused by elevated PM2.5 (particles with an aerodynamic diameter $<2.5 \mu \mathrm{m}$ ) concentrations, which is also known as PM2.5 pollution [4] [5]. Accordingly, "haze-fog" weather is considerable air pollution wherein the average visibility is less than $10 \mathrm{~km} \mathrm{[6].} \mathrm{During} \mathrm{haze-fog}$ days, low air visibility can lead to car accidents or diseases. Haze-fog affects many aspects of human life, which in turn decreases people's overall well-being.

Haze-fog has a serious impact on people's health, which is a major concern in human life. Accordingly, studies have been paying attention to the impact of haze-fog on human health. The most direct impact of haze-fog on human is respiratory diseases and increased cardiovascular diseases [7] [8] [9], atherosclerosis [10], and others [11] [12] [13].

Understanding the effects of haze-fog on human health is important for enhancing people's well-being in a rapidly urbanizing country [14]. Although the findings are very encouraging, there are still some limitations. For example, prior research heavily focuses on the influence of haze-fog on human health, whereas little is known about how it influences people's psychology and behavior. This is an important gap in the research. Marketers are eager to know which factors can influence consumers' psychology so that they can predict consumers' purchasing intention. There are many examples of how the environment can change consumers' psychological states and purchasing behavior. Thus, it is important to enrich the research on haze-fog. Without a comprehensive explanation of haze-fog, it would be difficult to clarify how haze-fog influences other aspects of human life.

To address this gap in the research, we explored the relationship between haze-fog and consumer psychology and behavior. In this paper, we focus on consumers' defensive psychology and the desire for money. We designed an experiment to examine our hypotheses. Overall, this study contributes to the literature in three ways. First, our study explores the effects of haze-fog on consumers' desire for money. Second, our study highlights the mediating effect of people's defensive psychology on the relationship between haze-fog and consumers' desire for money. Finally, we explored which purchasing behavior is more salient in the haze-fog environment. In particular, this study findings should raise awareness among the head of the company and governors that haze-fog is not only a pollution phenomenon but also a business opportunity. Therefore, understanding consumer psychology and behavior is helpful to arouse the attention of them and take actions in a positive direction.

\section{Hypothesis Development}

\subsection{Haze-Fog and Consumers' Desire for Money}

Money has three unique attributes: It serves as the unit of account, a store of 
value, and the medium of exchange [15]. That is, money has value and is used as a tool to meet people's aspirations and needs [16] [17] [18]. It is considered to be the most important property in a person's life [19].

Desire for money is defined as the motivation to have, hold, and obtains money [19]. Especially in a place of poverty, people are desperate for money to make their lives better [20]. People regard money as an important thing, and most of Chinese are willing to obtain money much more than to spend it [21]. Urban air pollution has gradually become prominent in China [22], especially haze-fog, which has not just resulted in visibility impairment, air quality degradation and health damage [23] but has also reduced the feeling of happiness among urban residents [24]. It has been reported that marketers have sold "fresh air" to people on haze-fog days, declaring that it came from a place with fresh air, such as Shandong province or even New Zealand, and many people were willing to pay for it. The negative effect of haze-fog is much stronger than the attraction to money to the point that, to weaken the negative impact of haze-fog, individuals are willing to reduce their desire for money in order to buy things related to haze-fog. That is, individuals are more willing to reduce their desire for money to buy something or behave in a certain way related to haze-fog for the purpose of reducing the negative impact of haze-fog.

Accordingly, the following hypotheses were proposed:

Hypothesis 1: Haze-fog is negatively related to consumers desire for money, wherein the desire is weaker when haze-fog is more severe.

\subsection{Haze-Fog and Defensive Psychology}

Haze-fog can be regarded as a possible source of stress such that it can produce discomfort. According to the regulatory focus theory, we define defensive psychology as the use of certain strategies to maintain a positive, consistent, and steady state when experiencing pressure or negative emotions. The phenomena observed in life and previous studies have confirmed the following: 1) haze-fog leads to health problems and increases fear of death, anxiety, insecurity, and other negative emotions [25] [26], and all of these negative emotions can be regarded as the fear of losing; 2) the aim of defensive psychology is to reduce the impact of haze-fog on individuals and strengthen their sense of self-protection, which improves personal awareness to alleviate the impact of haze-fog on them; and 3) when people engage in consumer behavior, most of them focus on buying products that can reduce the influence of haze-fog on individuals, exercising to enhance physical fitness, migrating to cities or countries with a better living environment, or alleviating their fear of death through purchasing behavior, measures that can reduce personal defensive psychology, which is evoked by haze-fog. Individuals are aware that discomfort is a significant challenge for which they must adjust their external or internal cognitive demands. When there is haze-fog, anxiety, fear and other negative emotions generally occur [27]. Haze-fog is a threat to the individual, and when an individual lacks a defensive 
mechanism, they can be easily controlled by negative emotions (such as sadness or anxiety). Therefore, as the intensity of haze-fog increases, so too does the level of defensive psychology.

Accordingly, the following hypothesis is proposed:

Hypothesis 2: Haze-fog is positively related to consumers' defensive psychology.

\subsection{Defensive Psychology and a Mediator}

Haze-fog exposure itself cannot directly exert negative effects because people's response to the environment is largely due to individual perceptions and assessment effects [28]. In particular, haze-fog is a stress source that poses a hazard to the individual, and the individual assesses the haze-fog as a stressor and copes with it effectively [29]. This is to say that the extent to which an individual considers haze-fog as a source of stress might be related to the extent of the adverse effects of haze-fog on individuals.

The effect of haze-fog as either a source of stress or on account of its pathogenicity is indirect and complex; the adverse effect of haze-fog is determined by subjective adjustment in the process of cognition, and this process affects an individual's health response and their behavior for dealing with haze-fog in a subtle and complex manner. Haze-fog, as an important source of stimulation, first affects the consumer's subjective awareness. Consumers believe that haze-fog leads to some loss in the process of achieving their goals. Moreover, haze-fog leads to a loss for consumers along with negative emotions, such as anxiety. To avoid this loss, people's defensive psychology is evoked, at which point they engage in prevention-focused self-regulation to achieve their target state [2] [30]. During haze-fog days, individuals feel unpleasant because it triggers their defensive psychological state. Therefore, these individuals engage in certain actions to meet their goals, and the quickest and most effective way to achieve their goals is to purchase or take some action to prevent harm from haze-fog.

The following hypothesis is presented:

Hypothesis 3: Defensive psychology mediates the influence of haze-fog on consumers' desire for money.

Thus, in order to verify our hypotheses, we designed a scenario experiment which showed three different situations, and then we assigned people into different scenario to arouse their emotions and behavior. See section 3 for specific verification.

\section{Method}

\subsection{Sample}

In exchange for 10 Yuan, 115 adults took part in this study, described as "The Influence of Haze-fog on Human Life". We collected participants' personal information. All participants were over 18 years of age and were at least college students. They were aware of the existence of haze-fog and may have expe- 
rienced it, which was helpful for the experiment. We excluded participants who responded within 120 seconds to make sure that everyone had taken sufficient time to complete the research. Finally, 7 participants did not meet the requirement, and 108 were qualified. For each condition, we had more than 30 participants; thus, the ratio of observations to independent variables was above 30:1, meeting the sample size requirements [31]. After that, we randomly classified the participants into three conditions. The distribution of participants is shown in Table 1.

\subsection{Manipulations}

Manipulations of the three conditions were based on the descriptions of the environment given in the Environmental Air Quality Index (AQI) Technical Requirements (for Trial Implementation) (HI 633-2012) shown in Table 2. The main components of haze-fog are $\mathrm{PM}_{2.5}$ and $\mathrm{PM}_{10}$. We considered the air quality shown in the picture as the measure of the degree of haze-fog. In this experiment, we presented three pictures, the main pollution in the pictures indicated by fine particles, and the objects in the description did not differ (as it shown in Picture 1). Here, the three pictures were presented as manipulations. In the experiment, the control group was presented with a sunny day condition, and the treatment groups were presented with the moderate pollution and severe pollution conditions. Participants were randomly assigned to one of the three between-subject conditions: 1) sunny day (as it shown in Picture 1(a)), 2) moderate pollution (as it shown in Picture 1(b)), and 3) severe pollution (as it shown in Picture 1(c)). Each condition represented a different level of pollution, and each picture had a short description above it. The details of each description are shown below. There were 35 participants in the sunny day condition, 35 in the moderate pollution condition, and 38 in the severe pollution condition.

Table 1. Pollution level picture ${ }^{\star}$ gender cross analysis.

\begin{tabular}{|c|c|c|c|c|}
\hline \multirow{2}{*}{\multicolumn{2}{|c|}{ Degree of Pollution }} & \multicolumn{2}{|c|}{ Gender } & \multirow{3}{*}{$\begin{array}{c}\text { Total } \\
35\end{array}$} \\
\hline & & \multirow{2}{*}{$\begin{array}{c}\text { Male } \\
17\end{array}$} & \multirow{2}{*}{$\begin{array}{c}\text { Female } \\
18\end{array}$} & \\
\hline Sunny Day & Account & & & \\
\hline \multirow{3}{*}{ Sunny Day } & Total Percentage & $15.7 \%$ & $16.7 \%$ & $32.4 \%$ \\
\hline & Account & 17 & 18 & 35 \\
\hline & Total Percentage & $15.7 \%$ & $16.7 \%$ & $32.4 \%$ \\
\hline \multirow{2}{*}{ Moderate Pollutio } & Account & 18 & 17 & 35 \\
\hline & Total Percentage & $16.7 \%$ & $15.7 \%$ & $32.4 \%$ \\
\hline \multirow{2}{*}{ Severe Pollutio } & Account & 15 & 23 & 38 \\
\hline & Total Percentage & $13.9 \%$ & $21.3 \%$ & $35.2 \%$ \\
\hline \multirow{2}{*}{ Total } & Account & 50 & 58 & 108 \\
\hline & Total Percentage & $46.3 \%$ & $53.7 \%$ & $100.0 \%$ \\
\hline
\end{tabular}

Notes. $N=108$. 
Table 2. Air quality grade, distribution index, and corresponding pollutant concentration limits and suggested activities.

\begin{tabular}{cccccccc}
\hline Air Quality Grade & First & Second & Third & Fourth & Fifth & Sixth \\
\hline Air Quality Status & & Excellent & Good & Slight Pollution & Moderate Pollution & Heavy Pollution & Severe Pollution \\
\hline (AQI) & 0 & 50 & 100 & 150 & 200 & 300 & 400 \\
PM $_{10}$ Density & 0 & 50 & 150 & 250 & 350 & 420 & 500 \\
PM2.5 Density & 0 & 35 & 75 & 115 & 150 & 250 & 300 \\
\hline
\end{tabular}

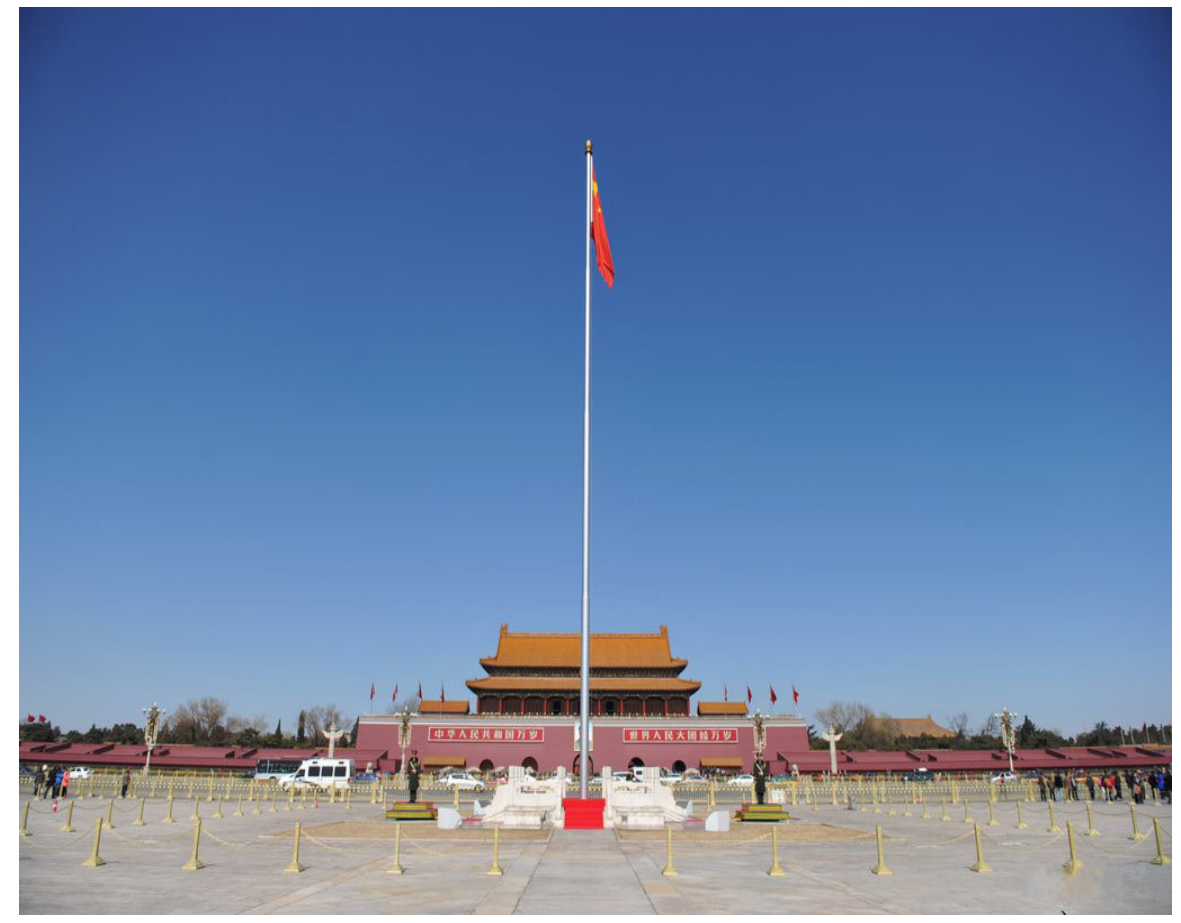

(a)

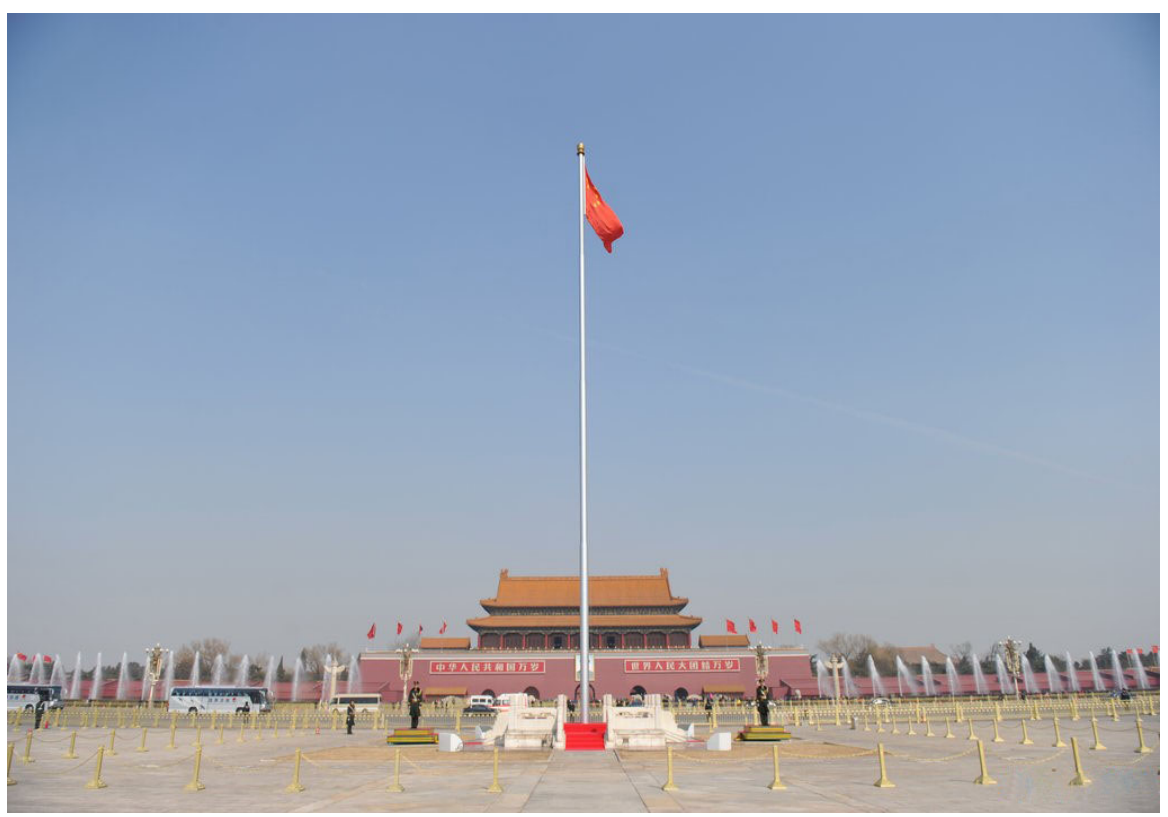

(b) 


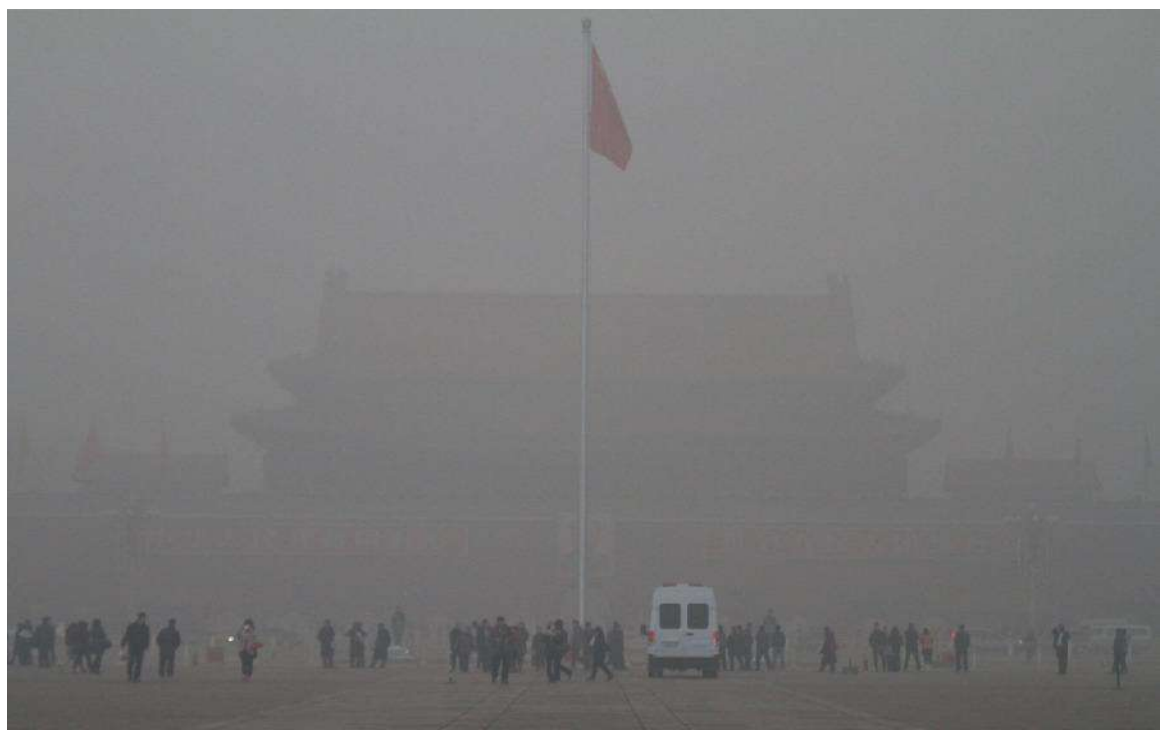

(c)

Picture 1. (a) Sunny Day: It is nice day with blue sky, fresh air, and warm sunshine The red flag raises slightly in the wind, the scenery is so clear and attractive; (b) Moderate Pollution: It is a nice day with grey sky, bad air, and warm sunshine. The red flag raises slightly in the wind, the scenery is not clear and attractive enough; (c) Severe Pollution: It is an awful day with black sky, awful air, and no sunshine. The red flag raises heavenly in the wind, the scenery is not clear and attractive any more.

\subsection{Mediator Variable}

Haze-fog leads to several types of psychological problems, and the unsafe atmosphere that it creates can lead to one's defensive psychology [32]. The classical manipulation method is to initiate defensive focus by establishing a "loss situation." For example, in the experiment, you can tell participants that "bad performance will be deducted." [33] [34] [35]. In our experience, the descriptions of the three conditions are different. The description of the sunny day is, "It is a nice day with a blue sky, fresh air, and warm sunshine. The red flag raises slightly in the wind. The scenery is so clear and attractive." The moderate haze-fog pollution is, "It is a nice day, with a gray sky, bad air, and warm sunshine. The red flag raises slightly in the wind. The scenery is not clear and attractive enough." The severe haze-fog pollution is, "It is an awful day, with a black sky, awful air, and no sunshine. The red flag raises heavily in the wind. The scenery is not clear and attractive at all." The differences among the three conditions are in the description of the sky, air, sunshine, red flag, and sceneries. Compared to the sunny day, the other two groups of participants did not stand in a good environment. The scenario contributes to a sense of loss. In this situation, many negative emotions will emerge.

To make the questions easier to understand and avoid confusion pertaining to the psychological measurements caused by the subjects, we only measured consumers' feelings caused by the haze-fog. Psychology involves cognition and emotion; personal negative mood caused by haze-fog cannot be quantified. 
Therefore, we directly measured personal pleasant feelings perceived from the pictures of haze-fog (as it shown in Picture 1). "Pleasant" refers to the subject feeling interested, satisfied, hopeful, happy, and other positive emotions when viewing the picture. By contrast, anger, anxiety, threat, and other negative emotional states were used to indicate unpleasant feelings. Participants completed the mediator measure "degree of pleasantness" ( 1 = very unpleasant, $4=$ somewhat, $7=$ very pleasant) and manipulation check "degree of pollution you perceived" ( 1 = no pollution, 2 = excellent, $3=$ good, $4=$ slight pollution, $5=$ moderate pollution, 6 = heavy pollution, $7=$ severe pollution). A score of " 1 " indicated "very unpleasant," while " 7 " indicated "very pleasant." Here, we used it to represent participants' level of defensive psychology in the current environment, with scores ranging from 1 to 7 .

\subsection{Dependent Variables}

Haze-fog affects consumers' behavior in many ways. It hinders consumers' outside activities and leads to a change in consumers' options. As shown in several studies and media reports, haze-fog has a serious influence on individual health. Protective equipment, such as masks [3], have become a necessity during haze-fog days. Air purifiers have become a common home appliance [3]. Individuals, who in order to enhance their physique or counteract the impact of haze-fog, prefer to exercise more, buy fitness-related products, or regularly go to the gym to enhance personal resistance when the weather is bad. Consumers are even willing to buy medical supplies in advance in order to monitor and maintain their own bodily functions to prevent harm. At the same time, consumers in a good economic situation might migrate to cities or countries with better air quality. The impact of haze-fog may also promote personal philanthropy or positive environmental attitudes. Several social media personalities pay more attention to environmental issues, and some of them have already made charitable donations to cope with environmental issues. There are several types of donations, and different charitable organizations may accept different types of donations under various names. Environmental protection will be a key type of donation in the future. Haze-fog is a major type of air pollution in China at present, and it has led people to pay more attention to environmental protection and be more willing to take part in charitable donations. Messages pertaining to environmental attitudes can be directly printed on products by manufacturers according to personal interests and business activities. Personal attitudes can be conveyed through tee shirt slogans, wherein the manufacturer can produce related products. Tee shirts are a good option for both sides, and consumers can choose these products. Studies have shown that experiencing a serious catastrophe can lead to individuals' fear of death [36]. Severe haze-fog to some extent is a serious natural disaster. A few deaths are inevitable, no matter the extent to which the media or researchers report the serious impact of haze-fog on human lives. When people think of death, individuals often feel anxious and depressed 
[37]. A risk of death has been shown to increase consumers' intention to purchase domestic goods [38] [39] [40]. This risk also encourages individuals' compensatory consumption [41]. Consumers, in order to mitigate the impact of haze-fog, purchase items or products intended for enjoyment, such as food or other luxuries, which exceed their budget [42].

In this experiment, participants were asked to imagine themselves in the condition shown in the picture, and they responded to the following two sets of items that assessed their desire for money. We used the average scores on these two sets of items," Concentration of interest" and "Purchase intention," as independent variables to represent the degree of consumers' desire for money. These sets were rated on a scale from 1 to $7(1=$ not at all, $4=$ somewhat, $7=$ extremely). Higher scores indicated a weaker desire for money. Following each question, 10 products were listed as dependent variables and included masks, an air purifier, a charitable donation, domestic skin care products, strength exercises, foods, medical supplies, slogan tees, migrating to cities or countries with cleaner air, and luxuries.

\subsection{Control Variables}

Because haze-fog can affect people along varying degrees, an individual's current psychological state affects their subjective judgment about the environment and how pleasant they find a given picture. Haze-fog has a stronger impact on sensitive people (mainly children and the elderly) and people suffering from physical diseases; therefore, this study focused on the investigation of adults. This age group has strong personal resistance, is in good health, has a certain understanding of haze-fog, and has better judgement.

At the end of the experiment, we asked participants to report their demographic variables, including gender, age, educational background, personal consumption per month, and residence.

\section{Results}

\subsection{Manipulation Checks}

Manipulation checks were intended to understand whether consumers had differing perceptions of the pictures at different levels of pollution. The perception of the sunny day condition was significantly less negative than those of the moderate pollution and severe pollution conditions $\left(M_{\text {sunny days }}=2.57, M_{\text {moderate }}\right.$ pollution $\left.=4.34, M_{\text {severe pollution }}=6.47, F(2,105)=116.327, p<0.01\right)$, and the results are in line with the level of pollution shown in the pictures, which indicate that the experimental manipulation was effective.

\subsection{Main Effect}

For each product or behavior, we tested the reliability of the two items used to measure participants' desire for money. For all products or behaviors, Cronbach's alpha values were greater than 0.7. In addition, Cronbach's Alphas for 
strength exercises, food, and slogan tee were between 0.7 and 0.8 . Other values were above 0.8, and Cronbach's alphas for air purifier and masks were close to 0.9 . Therefore, the measurements of these 10 products or behaviors demonstrated good reliability. We calculated average scores for the two sets of questions regarding desire for money. To test hypothesis 1 , the data were analyzed using SPSS 23.0 (for ANOVA) and JAMOVI 0.9.1.6 (for effect size). We followed guidelines provided in Nimon and colleagues to ensure that our data met the statistical assumptions associated with the general linear model-based statistical tests that we employed [43] [44].

As shown in Table 3, the average scores for mask $\left(M_{\text {sunny day }}=3.10, M_{\text {moderate }}\right.$ pollution $=5.04, M_{\text {severe pollution }}=6.17, F(2,105)=34.18, p<0.01, p \eta^{2}=0.394, \omega^{2}=$ $0.381)$, air purifier $\left(M_{\text {sunny day }}=3.10, M_{\text {moderate pollution }}=4.41, M_{\text {severe pollution }}=5.96\right.$, $\left.F(2,105)=27.52, p<0.01, p \eta^{2}=0.344, \omega^{2}=0.329\right)$, medical supplies $\left(M_{\text {sunny day }}=\right.$ 2.93, $M_{\text {moderate pollution }}=3.81, M_{\text {severe pollution }}=4.74, F(2,105)=12.21, p<0.01, p \eta^{2}=$ $\left.0.189, \omega^{2}=0.172\right)$, and migrating to cities or countries with cleaner air $\left(M_{\text {sunny day }}\right.$ $=3.79, M_{\text {moderate pollution }}=3.99, M_{\text {severe pollution }}=5.49, F(2,105)=10.67, p<0.01, p \eta^{2}=$ $\left.0.169, \omega^{2}=0.152\right)$ were significant. Strength exercises $\left(M_{\text {sunny day }}=5.14, M_{\text {moderate }}\right.$ pollution $=4.94, M_{\text {severe pollution }}=4.00, F(2,105)=4.27, p<0.05, p \eta^{2}=0.075, \omega^{2}=$ 0.057) showed a significant effect, but it did not support our hypothesis. Rather, this result indicated that the more severe the haze-fog was, the weaker individuals' willingness to exercise, and participants were less likely to reduce their desire to spend money on doing something related to exercise. Here, we just examined the items consistent with our hypothesis, so we did not examine "strength exercises" further. The five remaining effects were not significant. Based on the one-way analysis of variance, we concluded that consumers' desire to spend money on haze-fog related products was reduced, thereby partly confirming hypothesis 1 .

The three sets of scores corresponding to the feelings of pleasantness evoked by the pictures were $5.49,3.86$, and 2.05 for the sunny day condition, moderate pollution condition, and severe pollution condition, respectively. Therefore, the differences in pleasantness between the three groups were significant, indicating that the greater the intensity of haze-fog was, the lower individuals' pleasant scores. This is to say that, with increasing haze-fog intensity, consumers' level of defensive psychology became much stronger, thereby confirming hypothesis 2 .

\subsection{Mediation}

We predicted that an increase in haze-fog would decrease consumers' desire for money because such pollution increases their defensive psychology, which in turn leads to a greater willingness to spend money. To test this model, we used regression analysis with bootstrapping, using the PROCESS macro [45] [46]. In comparison to the classic mediation analysis of Baron et al. [47], PROCESS allows for testing direct and indirect effects in one model. Model 4 was applied to verify the research hypotheses (simple mediation). Applying bootstrapping technique 
Table 3. ANOVA of the examined items.

\begin{tabular}{|c|c|c|c|c|c|}
\hline Items & Conditions & $M$ & $S D$ & $F$ & $P$ \\
\hline \multirow{3}{*}{ Masks } & Sunny Day & 3.10 & 1.87 & \multirow{3}{*}{34.18} & \multirow{3}{*}{$0.000^{* x}$} \\
\hline & Moderate Pollution & 5.04 & 1.41 & & \\
\hline & Severe Pollution & 6.17 & 1.49 & & \\
\hline \multirow{3}{*}{ Air Purifier } & Sunny Day & 3.10 & 1.81 & \multirow{3}{*}{27.52} & \multirow{3}{*}{$0.000^{* *}$} \\
\hline & Moderate Pollution & 4.41 & 1.75 & & \\
\hline & Severe Pollution & 5.96 & 1.39 & & \\
\hline \multirow{3}{*}{$\begin{array}{l}\text { Charitable } \\
\text { Donation }\end{array}$} & Sunny Day & 3.43 & 1.58 & \multirow{3}{*}{2.77} & \multirow{3}{*}{0.067} \\
\hline & Moderate Pollution & 3.04 & 1.43 & & \\
\hline & Severe Pollution & 3.95 & 1.89 & & \\
\hline \multirow{3}{*}{$\begin{array}{l}\text { Domestic } \\
\text { Skin Care } \\
\text { Productions }\end{array}$} & Sunny Day & 3.57 & 1.75 & \multirow{3}{*}{0.03} & \multirow{3}{*}{0.971} \\
\hline & Moderate Pollution & 3.53 & 1.85 & & \\
\hline & Severe Pollution & 3.63 & 1.84 & & \\
\hline \multirow{3}{*}{$\begin{array}{l}\text { Strength } \\
\text { Exercise }\end{array}$} & Sunny Day & 5.14 & 1.44 & \multirow{3}{*}{4.27} & \multirow{3}{*}{$0.017^{\star}$} \\
\hline & Moderate Pollution & 4.94 & 1.53 & & \\
\hline & $\begin{array}{c}\text { Severe } \\
\text { Pollution }\end{array}$ & 4.00 & 2.25 & & \\
\hline \multirow{3}{*}{ Foods } & Sunny Day & 5.09 & 1.41 & \multirow{3}{*}{1.67} & \multirow{3}{*}{0.194} \\
\hline & Moderate Pollution & 4.50 & 1.19 & & \\
\hline & Severe Pollution & 4.93 & 1.55 & & \\
\hline \multirow{3}{*}{$\begin{array}{l}\text { Medical } \\
\text { Supplies }\end{array}$} & Sunny Day & 2.93 & 1.53 & \multirow{3}{*}{12.21} & \multirow{3}{*}{$0.000^{* *}$} \\
\hline & Moderate Pollution & 3.81 & 1.63 & & \\
\hline & Severe Pollution & 4.74 & 1.53 & & \\
\hline \multirow{3}{*}{ Slogan Tees } & Sunny Day & 3.40 & 1.76 & \multirow{3}{*}{0.34} & \multirow{3}{*}{0.712} \\
\hline & Moderate Pollution & 3.60 & 1.42 & & \\
\hline & Severe Pollution & 3.70 & 1.48 & & \\
\hline \multirow{3}{*}{$\begin{array}{l}\text { Migrating } \\
\text { to Cities or } \\
\text { Countries with } \\
\text { Cleaner Air }\end{array}$} & Sunny Day & 3.79 & 1.93 & \multirow{3}{*}{10.67} & \multirow{3}{*}{$0.000^{* x}$} \\
\hline & Moderate Pollution & 3.99 & 1.66 & & \\
\hline & Severe Pollution & 5.49 & 1.58 & & \\
\hline \multirow{3}{*}{ Luxuaries } & Sunny Day & 3.50 & 1.75 & \multirow{3}{*}{1.10} & \multirow{3}{*}{0.336} \\
\hline & Moderate Pollution & 3.14 & 1.65 & & \\
\hline & Severe Pollution & 2.95 & 1.41 & & \\
\hline
\end{tabular}

Notes. $N=108$; SD: Standard Deviation, ${ }^{*} p<0.01,{ }^{*} p<0.05$.

(5000 samples), PROCESS calculates direct, indirect, and global effects as well as their confidence intervals. As shown in Table 4, the mean indirect effect from the bootstrap analysis was positive and significant, with a 95\% bias-corrected and accelerated confidence interval excluding zero (LLCI-0.0102, ULCI-0.7597), 
Table 4. Mediation of pollution-level on consumers' desire to migrate to cities or countries with clear air mediated by defensive psychology ( 5000 bootstrap samples).

\begin{tabular}{|c|c|c|c|c|c|c|}
\hline \multicolumn{7}{|c|}{ Model summary } \\
\hline & \multirow{2}{*}{ Coeff. } & \multirow{2}{*}{$S E$} & \multirow{2}{*}{$t$} & \multirow{2}{*}{$p$} & \multicolumn{2}{|c|}{ Bootstrapping BCa $95 \% \mathrm{CI}$} \\
\hline & & & & & Lower & Upper \\
\hline Pollution-level & 0.8592 & 0.2048 & 4.1958 & 0.0001 & 0.4532 & 1.2652 \\
\hline \multicolumn{7}{|c|}{ Total effect of the Pollution-level on migration } \\
\hline \multirow{2}{*}{ Effect } & \multirow{2}{*}{$S E$} & \multirow{2}{*}{$t$} & \multirow{2}{*}{$p$} & \multicolumn{3}{|c|}{ Bootstrapping BCa 95\% CI } \\
\hline & & & & \multicolumn{2}{|l|}{ Lower } & Upper \\
\hline \multirow[t]{2}{*}{0.8592} & 0.2048 & 4.1958 & 0.0001 & \multicolumn{2}{|l|}{0.4532} & 1.2652 \\
\hline & \multicolumn{6}{|c|}{ Direct effect of the Pollution-level on migration } \\
\hline \multirow{2}{*}{ Effect } & \multirow{2}{*}{$S E$} & \multirow{2}{*}{$t$} & \multirow{2}{*}{$p$} & \multicolumn{3}{|c|}{ Bootstrapping BCa 95\% CI } \\
\hline & & & & \multicolumn{2}{|l|}{ Lower } & Upper \\
\hline \multirow[t]{2}{*}{0.5109} & 0.2963 & 1.7240 & 0.0876 & \multicolumn{2}{|l|}{-0.0767} & 1.0985 \\
\hline & \multicolumn{6}{|c|}{ Indirect effect of the Pollution-level on migration } \\
\hline \multirow{2}{*}{ Total } & \multirow{2}{*}{ Eeffct } & \multirow{2}{*}{\multicolumn{2}{|c|}{ SEs }} & \multicolumn{3}{|c|}{ Bootstrapping BCa 95\% C } \\
\hline & & & & \multicolumn{2}{|l|}{ Lower } & Upper \\
\hline $\begin{array}{l}\text { Defensive } \\
\text { Psychology }\end{array}$ & \multicolumn{2}{|l|}{0.3483} & 0.1912 & \multicolumn{2}{|l|}{0.0102} & 0.7597 \\
\hline
\end{tabular}

Notes. CIs are confidence intervals for effect sizes. $\mathrm{N}=108$.

indicating that the mediation effect of defensive psychology was significant. The mediation effect was 0.3483 . In addition, after controlling for the intermediary variable of defensive psychology, the influence of the independent variable (haze-fog level) on the dependent variable (migrating to cities or countries with cleaner air) was not significant, and the confidence interval contained zero (LLCI-0.0767, ULCI-1.0985). Therefore, defensive psychology played a mediating role in reducing consumers' desire for spending money on migrating to cities or countries with cleaner air, and it only acted as an intermediary variable between them. However, the mediating effect of defensive psychology on spending money on other products or engaging in preventive behaviors was not supported. Even the effect size of migration was not the most significant one. The first reaction people have when facing haze-fog days is to protect themselves from injuries, for which masks, air purifiers and medical supplies are necessary, so their effect size is higher. However, when individuals experience haze-fog for a long time, they may consider migrating. In this process, their defensive psychology serves as a mediator. Therefore, hypothesis 3 was only partially verified; that is, defensive psychology only plays an intermediary role in consumer's willingness to migrate to cities or countries with cleaner air. 


\section{Discussion}

Prior research on air pollution mainly focuses on the impact of harmful substances in the air on human health, how to control air pollution, what negative emotions are caused by it, and how to address it. However, little research has yet examined consumers' psychology and behavior in relation to haze-fog. In the present paper, we have linked the experience of haze-fog with personal and daily life, and individual psychology served as mediator.

As our experiment shows, when individuals suffer from severe haze-fog, they display a strong tendency to migrate to cities or countries with cleaner air, and this drives them to give up the life they are living, even if their salary is very high and despite the fact that migrating to other cities or countries involves heavy expenditures by individuals or families. When the damage from haze-fog is more serious than individuals' current state, they will consider migrating along with their family to a better place where the environment is much better. Although the moving process may cost more money, the improved environment is anticipated to compensate individuals and their families for those expenditures.

Severe haze-fog can lead individuals to experience a strong sense of unpleasantness, including depression, anxiety, and other negative emotions, which is a manifestation of individual psychology, a trigger that evokes people's defensive psychology. Individuals make purchases in a variety of ways to avoid harm by compensatory consumption, impulsive consumption, and so on. Due to the experimental design and its deviation in understanding along with other issues that this paper did not explore, such as use of masks, air purifiers, and other luxuries, the experimental results have not been effectively confirmed.

\subsection{Limitations}

Due to the limitations in the experimental conditions, this experiment could not be conducted in a real environment or simulation laboratory. The participants could only view visual pictures and read condition descriptions, which implied that they could not engage in the real environment. The individuals were unable to experience their cognitive and emotional reactions to haze-fog accurately. As a result, the experiment could not trigger negative emotions in them, and the participants could not experience corresponding psychological feelings regarding the intention to engage in purchasing behavior. For example, for food items, individuals may think that they must go out and buy food on severe haze-fog days, but the real intention indicated that consumers were willing to store more food in order to reduce the frequency of going out on haze-fog days.

Second, the experiment did not control for whether the subjects carefully read the questions and options or answered the questions seriously.

Finally, because the experiment was not conducted in a laboratory, we were not able to explain the willingness to purchase items when participants did purchase them. As such, this outcome caused personal cognitions regarding these items to deviate from the true meaning of these items, and it caused the experi- 
mental results to differ from the expected results. Regarding the item of exercise, as a first reaction, participants might think that they do not have to spend money on exercise, as it is an outdoor activity; thus, they reduced exercise on haze-fog days. However, the aim of this item was to examine participants' willingness to spend more money on buying fitness equipment for indoor exercise or on a fitness card to go to the gym for exercise during haze-fog days. This discrepancy also led to unsatisfactory results.

However, despite the unsatisfactory results of the experiment, the data showed that haze-fog indeed weakened consumers' desire to save money on goods or engage in behaviors that directly related to haze-fog.

\subsection{Academic Significance}

The present paper has great academic significance. Studies have shown that defensive psychology is evoked when facing negative situations, for which people use various strategies (most of which are unconscious) to protect themselves. Currently, scholars regard defensive psychology as both an unconscious and conscious process. In reality, when we face a threat, the first reaction we have is to protect ourselves from damage. Then, we consider changing the negative situation and take some action to regain our balance. This phenomenon is a conscious process. This study regards consumer psychology as a conscious process to describe the relationship between haze-fog and consumers' weak desire for money, and it enriched the psychological understanding of regulatory focus theory.

\subsection{Practical Significance}

The topic has important practical significance. This article, which was based on Chinese reality, analyzed states from the existing research on haze-fog and discusses its impact on individuals' desire for money. The study involves a new way to think about haze-fog, and its linking of haze-fog with different areas has presented a new way of thinking. The effect of haze-fog on individuals does not only compel them to buy masks, air purifiers, and other products; it has a more profound impact. Due to the limitations of the experimental content and the discrepancy in understanding the items it represented, the experimental results were not very good.

The results of the present paper can help leaders pay more attention to brain drain. Talent is a big problem in our country. Due to the uneven population distribution, most of the population is in the eastern region, and so too are the talented. In the east, there are more jobs, robust infrastructure, and opportunities for people to realize their dreams, but the eastern region is suffering from haze-fog. Different cities have different kinds of talent introduction programs. Environmental problems are a great challenge for countries and companies, and both of them must address many things to maintain highly talented technicians. Many people care about where they live, what they can obtain, and how they can 
improve their lives when they stay in a place. With the higher cost of living in first-tier cities and serious environmental pollution, second- and third-tier cities offer more preferential policies for the influx of talent and less living pressure. As such, the possibility of talent from first-tier cities transferring to second- and third-tier cities is increasing. It is difficult to determine if more talented individuals want to go to places with better environments, but this possibility should be considered by leaders.

It is a challenge and yet an opportunity for real estate developers. Most people want to live in a place with an excellent environment, but in places with severe haze-fog, few good environments remain. An increasing number of Chinese individuals have become richer, and most live in first-tier cities. Many of those wealthy Chinese care about the environment in which they live, and this is the same for normal persons who live there. It is a challenge for real estate developers to find a place for people to live in heavily polluted areas, and it is also a good opportunity for them to come up with some good ideas to address this problem. These developers can build ecological homes or develop an ecosystem. Although these efforts increase the cost of living, I think that someone who wants to live there would be willing to pay for it.

\section{Conclusions}

This experiment shows that haze-fog influences consumers' behaviors with regard to migrating to countries or cities with clean air and that their defensive psychology serves as mediator. We asked participants to focus on the condition shown in a set of pictures. This method has some limitations, as the participants did not perceive real environments. As such, the participants could not understand the real meaning of the items presented. This lack of understanding led to deviations from the expected results. Nevertheless, haze-fog does not just evoke consumers' defensive psychology; it stokes some other thought processes as well. For example, as the environment is always full of fine particles, it becomes a part of one's life and is a normal thing. We may ignore this pollution, and haze-fog causes no obvious psychological changes. We may even regard sunny days as abnormal events in life. After exposure to haze-fog for a long period of time, one is eager to seek support from society. This situation evokes consumers' nostalgia and leads them to engage in purchasing behavior.

Haze-fog is a type of risk whereby prolonged exposure to it may cause diseases. In recent days, welfare involves not only risk management but also management of environmental problems. In terms of its link with humans, different people have different levels of risk perception regarding haze-fog [48] [49] [50]. Some people regard haze-fog as a disaster, and some view it as a normal thing in daily life. Some even ignore it, which leads to different decisions [2].

\section{Future Direction}

Future research can explore the association between risk perception and decision 
making regarding haze-fog. Scholars should verify the relationship between haze-fog and consumer behavior by examining other mediators.

\section{Ethics Approval and Consent to Participate}

All procedures performed in studies involving human participants were in accordance with the ethical standards of the institutional and national research committee and with the 1964 Helsinki declaration and its later amendments or comparable ethical standards.

\section{Acknowledgements}

None.

\section{Conflicts of Interest}

The authors declare no conflicts of interest regarding the publication of this paper.

\section{References}

[1] Huang, M., Hu, S. and Su, X. (2013) Exploring the Relation between the Urbanization and Urban Employment in China Based on Panel Data and Time Series. Ninth International Conference on Natural Computation (ICNC), Shenyang, 23-25 July 2013, 1814-1819.

[2] Zhang, Y. (2016) Urbanization, Inequality, and Poverty in the People's Republic of China. Social Science Electronic Publishing. https://doi.org/10.2139/ssrn.2838056

[3] Zheng, S. and Kahn, M.E. (2017) A New Era of Pollution Progress in Urban China? Journal of Economic Perspectives, 31, 71-92. https://doi.org/10.1257/jep.31.1.71

[4] Chan, C.K. and Yao, X. (2008) Air Pollution in Mega Cities in China. Atmospheric Environment, 42, 1-42. https://doi.org/10.1016/j.atmosenv.2007.09.003

[5] Yu, S., Zhang, Q., Yan, R., Wang, S., Li, P., Chen, B., Liu, W. and Zhang, X. (2014) Origin of Air Pollution during a Weekly Heavy Haze Episode in Hangzhou, China. Environmental Chemistry Letters, 12, 543-550. https://doi.org/10.1007/s10311-014-0483-1

[6] Geng, F., Liu, Q., Chen, Y., Hua, Z. and Mao, X. (2011) Preliminary Study of Vertical Distribution of Aerosols during Dry Haze Periods around Shanghai Based on CALIPSO. Procedia Earth \& Planetary Science, 2, 217-222. https://doi.org/10.1016/j.proeps.2011.09.035

[7] Chang, X., Zhou, L., Tang, M. and Wang, B. (2015) Association of Fine Particles with Respiratory Disease Mortality: A Meta-Analysis. Archives of Environmental \& Occupational Health, 70, 98-101. https://doi.org/10.1080/19338244.2013.807763

[8] Dabass, A., Talbott, E.O., Venkat, A., Rager, J., Marsh, G.M., Sharma, R.K. and Holguin, F. (2016) Association of Exposure to Particulate Matter (PM2. 5) Air Pollution and Biomarkers of Cardiovascular Disease Risk in Adult NHANES Participants (2001-2008). International Journal of Hygiene and Environmental Health, 219, 301-310. https://doi.org/10.1016/j.ijheh.2015.12.002

[9] Nascimento, A.P., Santos, J.M., Mill, J.G., Souza, J.B.D., Júnior, R., Costa, N. and Reisen, V.A. (2017) Association between the Concentration of Fine Particles in the Atmosphere and Acute Respiratory Diseases in Children. Revista de Saude Publica, 
51, 3. https://doi.org/10.1590/s1518-8787.2017051006523

[10] Kim, J.Y., Park, K.H., Kim, S.M., Lee, E.Y., Kim, S.H. and Cho, K.H. (2015) Particulate matter2.5 (PM2.5) Exacerbates Atherosclerosis and Cellular Senescence via Aggregation and Proteolytic Degradation of Serum Lipoproteins. Atherosclerosis, 241, e94. https://doi.org/10.1016/j.atherosclerosis.2015.04.327

[11] Guo, P., Feng, W., Zheng, M., Lv, J., Wang, L., Liu, J., Zhang, L., et al. (2018) Short-Term Associations of Ambient Air Pollution and Cause-Specific Emergency Department Visits in Guangzhou, China. Science of the Total Environment, 613, 306-313. https://doi.org/10.1016/j.scitotenv.2017.09.102

[12] Liu, C.W., Lee, T.L., Chen, Y.C., Liang, C.J., Wang, S.H., Lue, J.H., Chen, Y.L., et al. (2018) PM 2.5-Induced Oxidative Stress Increases Intercellular Adhesion Molecule-1 Expression in Lung Epithelial Cells through the IL-6/AKT/STAT3/NF $\kappa \mathrm{B}$-Dependent Pathway. Particle and Fibre Toxicology, 15, 4.

https://doi.org/10.1186/s12989-018-0240-x

[13] Yu, S., Li, P., Wang, L., Wu, Y., Wang, S., Liu, K., Wong, D.C., Pleim, J., Mathur, R., Rosenfeld, D. and Seinteld, J.H. (2018) Mitigation of Severe Urban Haze Pollution by a Precision Air Pollution Control Approach. Scientific Reports, 8, Article No. 8151. https://doi.org/10.1038/s41598-018-26344-1

[14] Gu, D., Huang, N., Zhang, M. and Wang, F. (2015) Under the Dome: Air Pollution, Wellbeing, and Pro-Environmental Behaviour among Beijing Residents. Journal of Pacific Rim Psychology, 9, 65-77. https://doi.org/10.1017/prp.2015.10

[15] Yermack, D. (2018) The Potential of Digital Currency and Blockchains. NBER Reporter, National Bureau of Economic Research (NBER), Cambridge, 14-17.

[16] Lin, Y.T. (2018) New Concepts of Equality of Educational Opportunity. Universal Journal of Educational Research, 6, 399-403. https://doi.org/10.13189/ujer.2018.060306

[17] Mansour, E. (2018) Profiling Information Needs and Behaviour of Syrian Refugees Displaced to Egypt: An Exploratory Study. Information and Learning Science, 119, 161-182. https://doi.org/10.1108/ILS-08-2017-0088

[18] Mohapatra, M. and Sahu, P. (2018) Building a Sustainable Talent Acquisition Model in a Dynamic Business Environment. International Journal of Human Capital and Information Technology Professionals, 9, 42-52. https://doi.org/10.4018/IJHCITP.2018070103

[19] Lasaleta, J.D., Sedikides, C. and Vohs, K.D. (2014) Nostalgia Weakens the Desire for Money. Journal of Consumer Research, 41, 713-729. https://doi.org/10.1086/677227

[20] Dunor, H. and Urassa, J.K. (2017) Access to Reproductive Health Services and Factors Contributing to Teenage Pregnancy in Mtwara Region, Tanzania. Developing Country Studies, 7, 30-41.

[21] Liu, H.M., Zhou, X., Wu, C.H. and Wang, K.Q. (2018) An Empirical Study on the Impact of Population Aging on Residents' Savings in Shanghai. East China Economic Management, 32, 19-25. (In Chinese)

[22] Xie, X., Tou, X. and Zhang, L. (2017) Effect Analysis of Air Pollution Control in Beijing Based on an Odd-and-Even License Plate Model. Journal of Cleaner Production, 142, 936-945. https://doi.org/10.1016/j.jclepro.2016.09.117

[23] Kan, H., Chen, R. and Tong, S. (2012) Ambient Air Pollution, Climate Change, and Population Health in China. Environment International, 42, 10-19. https://doi.org/10.1016/j.envint.2011.03.003

[24] Zhang, H., Wang, S., Hao, J., Wang, X., Wang, S., Chai, F. and Li, M. (2016) Air 
Pollution and Control Action in Beijing. Journal of Cleaner Production, 112, 1519-1527. https://doi.org/10.1016/j.jclepro.2015.04.092

[25] Cameron, W.B. and McCormick, T.C. (1954) Concepts of Security and Insecurity. American Journal of Sociology, 59, 556-564. https://doi.org/10.1086/221442

[26] Gilal, F.G., Gilal, R.G. and Gilal, R.G. (2014) Romanticism vs. Antagonism: Battle of Minds, a Case of Beijing Pollution. Journal for Multidimensional Education, 6, 57-78. https://doi.org/10.18662/rrem/2014.0602.05

[27] Eley, T.C. and Stevenson, J. (2000) Specific Life Events and Chronic Experiences Differentially Associated with Depression and Anxiety in Young Twins. Journal of Abnormal Child Psychology, 28, 383-394. https://doi.org/10.1023/A:1005173127117

[28] Day, R.J. (2006) Traffic-Related Air Pollution and Perceived Health Risk: Lay Assessment of an Everyday Hazard. Health Risk \& Society, 8, 305-322. https://doi.org/10.1080/13698570600871869

[29] Kaufman, J.D., Adar, S.D., Allen, R.W., Barr, R.G., Budoff, M.J., Burke, G.L. and Tracy, R.P. (2012) Prospective Study of Particulate Air Pollution Exposures, Subclinical Atherosclerosis, and Clinical Cardiovascular Disease: The Multi-Ethnic Study of Atherosclerosis and Air Pollution (MESA Air). American Journal of Epidemiology, 176, 825-837. https://doi.org/10.1093/aje/kws169

[30] Higgins, E.T. (1987) Self-Discrepancy: A Theory Relating Self and Affect. Psychological Review, 94, 319-340. https://doi.org/10.1037/0033-295X.94.3.319

[31] Hair, J.F., Black, W.C., Babin, B.J. and Anderson, R.E. (2010) Multivariate Data Analysis: A Global Perspective. Pearson, Upper Saddle River.

[32] Chang, G.M., Cheng, S.H. and Tung, Y.C. (2010) A Multilevel Integration of Personality, Climate, Self-Regulation, and Performance. Personnel Psychology, 59, 529-557.

[33] Gino, F. and Margolis, J.D. (2011) Bringing Ethics into Focus: How Regulatory Focus and Risk Preferences Influence (un)ethical Behavior. Organizational Behavior and Human Decision Processes, 115, 145-156. https://doi.org/10.1016/j.obhdp.2011.01.006

[34] Kai, S., Landkammer, F. and Jacoby, J. (2014) The Influence of Regulatory Focus and Group vs. Individual Goals on the Evaluation Bias in the Context of Group Decision Making. Journal of Experimental Social Psychology, 54, 153-164. https://doi.org/10.1016/j.jesp.2014.05.009

[35] Mao, C. (2017) Regulatory Focus Theory: Application in Organizational Management Research. Advances in Psychological Science, 25, 682-690.

https://doi.org/10.3724/SP.J.1042.2017.00682

[36] Foust, M.A. (2013) Experience as a Prelude to Disaster: American Philosophy and the Fear of Death. Mortality, 18, 1-16. https://doi.org/10.1080/13576275.2012.753871

[37] Bodner, E., Shrira, A., Hermesh, H., Ben-Ezra, M. and Iancu, I. (2015) Psychiatrists' Fear of Death Is Associated with Negative Emotions toward Borderline Personality Disorder Patients. Psychiatry Research, 228, 963-965.

https://doi.org/10.1016/j.psychres.2015.06.010

[38] Fransen, M.L., Fennis, B.M., Pruyn, A.T.H. and Das, E. (2008) Rest in Peace? Brand-Induced Mortality Salience and Consumer Behavior. Journal of Business Research, 61, 1053-1061. https://doi.org/10.1016/j.jbusres.2007.09.020

[39] Friese, M. and Hofmann, W. (2008) What Would You Have as a Last Supper? Thoughts about Death Influence Evaluation and Consumption of Food Products. 
Journal of Experimental Social Psychology, 44, 1388-1394.

https://doi.org/10.1016/j.jesp.2008.06.003

[40] Liu, J. and Smeesters, D. (2010) Have You Seen the News Today? The Effect of Death-Related Media Contexts on Brand Preferences. Journal of Marketing Research, 47, 251-262. https://doi.org/10.1509/jmkr.47.2.251

[41] Kasser, T. and Sheldon, K.M. (2000) Of Wealth and Death: Materialism, Mortality Salience, and Consumption Behavior. Psychological Science, 11, 348-351. https://doi.org/10.1111/1467-9280.00269

[42] Zaleskiewicz, T., Gasiorowska, A., Kesebir, P., Luszczynska, A. and Pyszczynski, T. (2013) Money and the Fear of Death: The Symbolic Power of Money as an Existential Anxiety Buffer. Journal of Economic Psychology, 36, 55-67. https://doi.org/10.1016/j.joep.2013.02.008

[43] Nimon, K.F. (2012) Statistical Assumptions of Substantive Analyses across the General Linear Model: A Mini-Review. Frontiers in Psychology, 3, 322. https://doi.org/10.3389/fpsyg.2012.00322

[44] Patil, I., Young, L., Sinay, V. and Gleichgerrcht, E. (2016) Elevated Moral Condemnation of Third-Party Violations in Multiple Sclerosis Patients. Social Neuroscience, 12, 308-329. https://doi.org/10.1080/17470919.2016.1175380

[45] Preacher, K.J. and Hayes, A.F. (2008) Asymptotic and Resampling Strategies for Assessing and Comparing Indirect Effects in Multiple Mediator Models. Behavior Research Methods, 40, 879-891. https://doi.org/10.3758/BRM.40.3.879

[46] Hayes, A.F. and Preacher, K.J. (2013) Statistical Mediation Analysis with a Multicategorical Independent Variable. British Journal of Mathematical \& Statistical Psychology, 67, 451-470. https://doi.org/10.1111/bmsp.12028

[47] Baron, R.M. and Kenny, D.A. (1986) The Moderator-Mediator Variable Distinction in Social Psychological Research: Conceptual, Strategic, and Statistical Considerations. Journal of Personality and Social Psychology, 51, 1173-1182. https://doi.org/10.1037/0022-3514.51.6.1173

[48] Slovic, P. and Peters, E. (2006) Risk Perception and Affect. Current Directions in Psychological Science, 15, 322-325. https://doi.org/10.1111/j.1467-8721.2006.00461.x

[49] Bickerstaff, K. (2004) Risk Perception Research: Socio-Cultural Perspectives on the Public Experience of Air Pollution. Environment International, 30, 827-840. https://doi.org/10.1016/j.envint.2003.12.001

[50] Hine, D.W., Marks, A.D., Nachreiner, M., Gifford, R. and Heath, Y. (2007) Keeping the Home Fires Burning: The Affect Heuristic and Wood Smoke Pollution. Journal of Environmental Psychology, 27, 26-32.

https://doi.org/10.1016/j.jenvp.2007.01.001 